\title{
JAK-STAT Lodges in Multiple Sclerosis: Pathophysiology and Therapeutic Approach Overview
}

\author{
Kabir Magaji Hamid1 ${ }^{*}$, Abdullahi Isiyaku1 ${ }^{1}$, Mustapha Umar Kalgo', Isah Suleiman Yahaya ${ }^{2}$, \\ Abbas Mirshafiey ${ }^{3}$
}

${ }^{1}$ Department of Immunology, Faculty of Medical Laboratory Sciences, Usmanu Danfodiyo University, Sokoto, Nigeria ${ }^{2}$ Department of Medical Laboratory Science, Faculty of Allied Health Sciences, Bayero University, Kano, Nigeria

${ }^{3}$ Department of Immunology, School of Public Health, Tehran University of Medical Sciences, Tehran, Iran

Email: *kmhamid@hotmail.co.uk

How to cite this paper: Hamid, K.M., Isiyaku, A., Kalgo, M.U., Yahaya, I.S. and Mirshafiey, A. (2017) JAK-STAT Lodges in Multiple Sclerosis: Pathophysiology and Therapeutic Approach Overview. Open Access Library Journal, 4: e3492.

https://doi.org/10.4236/oalib.1103492

Received: March 4, 2017

Accepted: April 24, 2017

Published: April 27, 2017

Copyright $\odot 2017$ by authors and Open Access Library Inc.

This work is licensed under the Creative Commons Attribution International License (CC BY 4.0).

http://creativecommons.org/licenses/by/4.0/

\begin{abstract}
Multiple sclerosis (MS) is a complex inflammatory and demyelinating disease of central nervous system (CNS). The disease pathogenesis is not fully understood and no actual cure for the disease yet. The disease has genetic and environmental cause as fundamental factors which are identified for the disease pathogenesis so far. One of the characteristic features of the disease is inflammation cause due to activation of pro-inflammatory cells. Interference in signalling pathways such as JAK/STAT could result in physiological or pathological outcome in MS. Dysregulation of JAK/STAT signalling pathway is associated with chronic inflammatory process and immune disorders. In this review, considering the important role of JAK/STAT pathway in signal transduction of inflammatory process and immune responses in CNS, we describe the involvement of this signal transduction pathway in MS. Moreover, we consider the physiological and pathological involvement of JAK/STAT rout in neurogenesis/gliogenesis, cytokines production and as therapeutics target for managing MS.
\end{abstract}

\section{Subject Areas}

Immunology, Neurology, Neuroscience

\section{Keywords}

Cytokines, Janus Kinases, Multiple Sclerosis, Neurogenesis, Signal Transduction, Transcription Factors

\section{Introduction}

Multiple sclerosis (MS) is an inflammatory, demyelinating, and neurodegenera- 
tive disease of the central nervous system [1]. MS attacks the myelinated axons in the central nervous system (CNS), destroying the myelin and axons to various degrees [2]. The pathologically distinguishing features of the disease are demyelination, axonal loss and inflammation [3]. The disease affects around 2.5 million people worldwide [4] and is commonly found in young adults, and it is more common in women [5]. Clinically, the major signs and symptoms of MS are cognitive disabilities [6], abnormal sensation, weakness, paralysis, incoordination, and ocular symptoms associated with relapses and remissions [7]. Although the etiology of MS is still unknown and its pathogenetic pathways are not fully understood [8], there is evidence of the interplay between genetic susceptibility and environmental factors [9] [10]. Existing knowledge in MS pathology indicates that the pathological process is initiated by the role of autoreactive myelin specific CD4+ T helper (Th) cells type 1 and Th17 cells and to some extent by other cell types like, CD8+ T cells, B cells, macrophages and natural killer (NK) cells [11]. Moreover, transmigration of inflammatory lymphocytes into the CNS induces an inflammatory response, which results into destruction of nearby tissue, demyelination and neurological damage [1] [12].

The Janus kinase (JAK)-signal transducer comprises of four cytoplasmic tyrosine kinases (JAK1, JAK2, JAK3 and TYK2), and the signal transducer and activator of transcription (STAT) identified in human cells are STAT1, STAT2, STAT3, STAT4, STAT5A, STAT5B and STAT6 [13] [14]. These intracellular signaling pathways are essential pleiotropic cascades used to transduce a multitude of signals for numerous physiologic and pathologic processes in animals and humans [15]. The JAK and STAT expression is low in CNS when compared with other systems and it is associated with gene regulation and inflammation [13]. Moreover, signal transduction through the pathway mediates inflammatory and immune responses in the CNS [16]. Although the evidence for the role of JAK in neuroinflammation is obscure, JAK/STAT signaling pathways play both detrimental and beneficial roles by promoting nerve damaging and CNS regeneration after the resulting inflammation has declined [17].

Dysregulation of STATs can be associated with deleterious biological processes such as chronic inflammation [18] [19] [20], cancer [21] and immune disorders [13], thus having the advantage of being therapeutic targets. The activation of JAK/STAT pathway in MS is possibly due to excessive production of cytokines, loss of expression of negative regulators such as Suppressor of cytokine signaling (SOCS) proteins, and significant enrichment of genes encoding components of the JAK/STAT pathway, including STAT3 [22]. This review describes the involvement of JAK/STAT signalling pathways in MS. We describe the role of the pathway in regulation of neurogenesis/gliogenesis, immune cells proliferation and differentiation, regulation of cytokines activation and therapeutic target potential of the pathway in MS.

\section{JAK/STAT System}

JAK-STAT signaling pathway is evolutionarily conserved in eukaryotes [13], 
which participate in important biological processes such as cell growth, differentiation, proliferation, survival, apoptosis and immune responses [23] thus are crucial in many cell types. The discovery of this pathway, especially in the field of cell biology, gives an explanation to the mechanism of gene regulation that significantly add more information on the action of hormones, interferons, colony-stimulating factors, and interleukins [24] together with its involvement in neurogenesis [25], glial differentiation [26] and CNS diseases [27] [28].

Structural overview: Structurally, each molecule of JAK contains seven JAK homology domains (JH1-7). The carboxyl JH1 domain is responsible for catalytic activity, whereas $\mathrm{N}$-terminal JH7 domain contains the receptor binding site (Figure 1). In contrast, $\mathrm{JH} 1$ and $\mathrm{JH} 2$ domains have significant homology but $\mathrm{JH} 2$ lacks enzymatic activity thus regarded as pseudo-kinase domain [14]. These kinases bind to the juxtamembrane region of cytokine receptors [29]. The seven

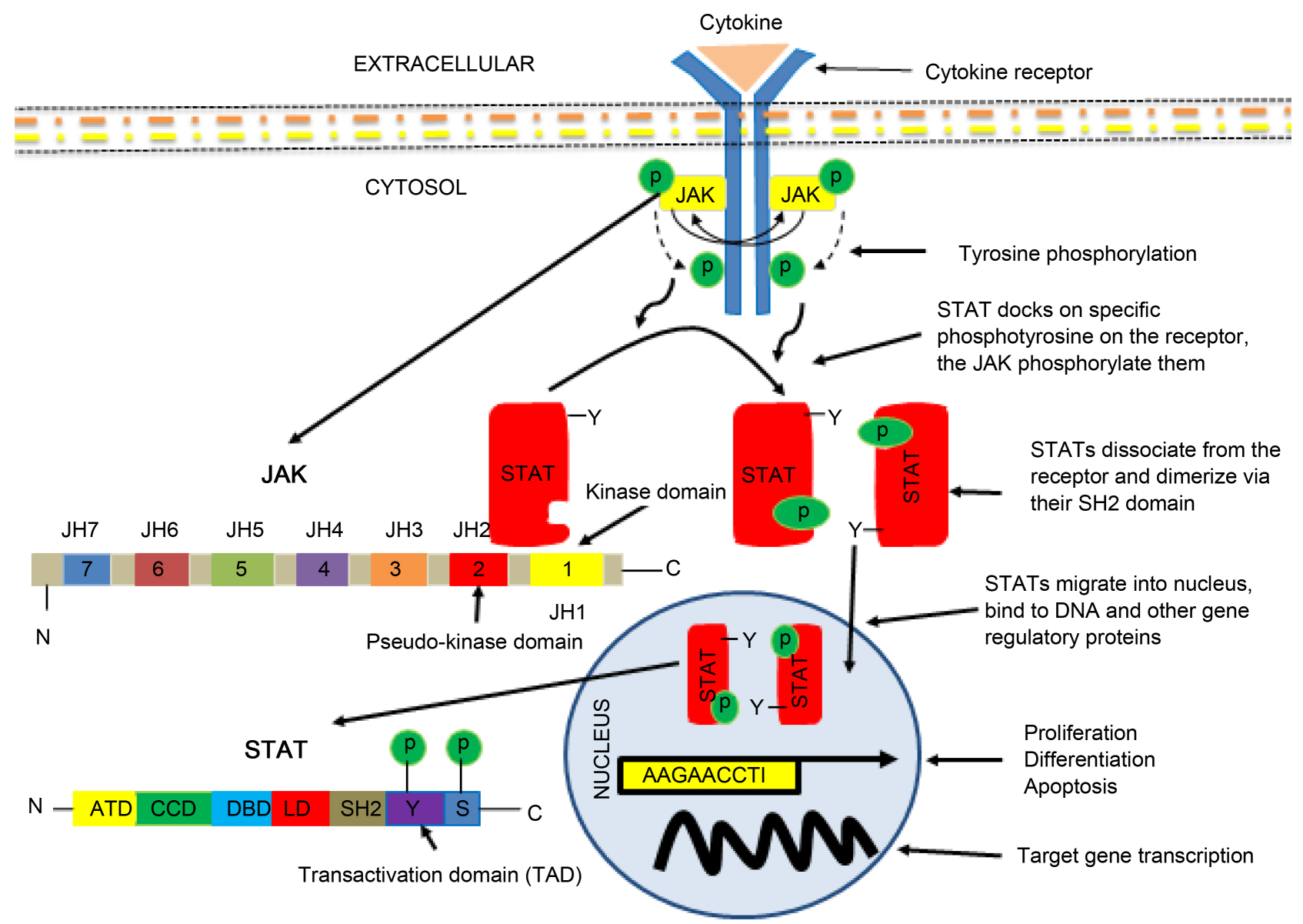

Figure 1. Model structure and signaling of JAK/STAT pathway. The pathway can be activated by cytokines. Binding of cytokine phosphorylate adjacent receptors, thus JAKs cross-phosphorylate each other on tyrosine. The activated JAKs phosphorylate receptors on tyrosine. This action leads to the enrollment of STAT protein to the receptor/kinase complex via SH2 domain of the STAT. The STAT is then tyrosine phosphorylated (Y) at a single residue in its C-terminus. The STAT can also be serine phosphorylated (S) in their TAD. The tyrosine phosphorylation of the STAT results in STAT dimerization via tyrosine (Y) and SH2 domain interaction. The STATs migrate into nucleus and bind to DNA and other gene regulatory proteins via their DNA-binding domain (DBD), this action leads to gene transcription in the nucleus. JAK homology (JH), amino terminal domain (ATD), coiled-coiled domain (CCD), DNA binding domain (DBD), linker domain (LD), transactivation domain (TAD). 
structurally and functionally mammalian STAT family have size range from 750 to 850 amino acids [30] and share conserved domains. This includes the amino-terminal domain (NH2), the coiled-coiled domain (CCD), the DNA binding domain (DBD), the linker domain and the SH2/tyrosine activation domain (Figure 1). In contrast, the carboxy-terminal transcriptional activation domain (TAD) differs and contributes to STAT specificity [31]. Moreover, SH2 as the most highly conserved STAT domain have the capacity to bind to specific phosphotyrosine motifs thus serve a significant role in signaling [31].

Activation: JAK/STAT pathway receptor is activated by cytokines, hormones or growth factors resulting in dimerization of the receptor and subsequent activation of JAK and phosphorylation of tyrosine residues [13] [32]. The activated JAK recruits and phosphorylates STAT on its conserved tyrosine residue [33]. The STAT then becomes dimerize and subsequently translocate into the nucleus where it will bind with DNA and regulate genes expression [23] (Figure 1). In contrast to other STATs, STAT5A/B are specifically activated in response to a variety of cytokines as well as tyrosine kinase receptors and were plausibly assumed that they have a basic role in cell growth regulation [35] [36]. Of note the STAT activation by non-cytokine receptor can be JAK- dependent or JAK independent however, it varies depends on receptors [23].

\section{JAK/STAT Pathways Involvement in Neurogenesis/Gliogenesis}

During proliferation and differentiation of brain cells, neural stem cells (NSC) or neural progenitor cells (NPC) mostly differentiate into neurons, astrocytes or oligodendrocytes in sub ventricular zone (SVZ) of olfactory bubs and dentate gyrus (DG) of the hippocampus of adult brain [37]. JAK/STAT pathway is associated with regulation of NSC proliferation. Adult NSC of the SVZ expresses IL-15 which plays role in activation of STAT1, 3 and 5, and NSCs proliferation which could be blocked by JAK inhibitors [38] [39]. JAK1 is probably involved in astrocytic differentiation [40], whereas, JAK2 seems more important for NSC proliferation [41] while JAK3 is reported to induce neuronal and oligodendroglial differentiation in NSCs [42]. Both in vitro and in vivo studies showed that activation of STAT3 and Akt by leptin results in regulation of neuroproliferation in the DG of adult mice [41]. Moreover in adult's DG, neurogenesis is reported to rely on STAT3 activation [43]. Interferon $\beta$, typically used in treatment of MS, can activate STATs [13] thus implicated in controversial role in proliferation and differentiation of NPC in murine [44], because it can either inhibit [45], have no effect [44] or enhance the proliferation of the NPC [46]. Previous study on the role of JAK-STAT in glial differentiation showed that activation of ciliary neurotrophic factor (CNTF) receptor is associated with activation of JAK1, STAT1 and STAT3 and stimulating the differentiation of embryonic cortical precursor cells into astrocytes [13]. Similarly JAK2, STAT1 and STAT3 activation is partly associated with proliferation and differentiation of astrocytes [47]. Moreover, a study showed that STAT3 knock-down mice enhanced neurogene- 
sis while blocking astrogliogenesis [25]. Inhibitory proteins of JAK-STAT pathway such as SOCS 2, 3 and 6 negatively regulate neuronal differentiation and neurite outgrowth after induction of insulin-like growth factor-1 (IGF-1) and growth hormone [48]. Previous study on SOCS2 knock out mice reported that overexpression of SOCS2 can blocks GH-signalling and impairs neurogenesis, whereas neuronal differentiation was increased [42].

STAT activation could lead to apoptosis [13], for example IFN- $\gamma$ activation of STAT1 affects NPCs by reducing its proliferation and inducing apoptosis via upregulation of p21 and caspase-3 signaling [49]. Rather IL-9 signaling protects neonatal neurons from apoptosis by activation of the JAK-STAT pathway [50]. Moreover, a study showed that in vitro treatment of IL-9 and AG490 activate STAT1 and STAT3, however this anti-apoptotic effect could be obstructed by possible inhibitor of JAK-STAT pathway in vivo [50]. Furthermore, STAT3 and STAT 5 are more anti-apoptotic than STAT1 [30]. However, the proportion of STAT1 activation over that of STAT3 and STAT5 seems to play a role in apoptosis [30]. JAK-STAT pathway plays a role in neuronal regeneration and glia scar formation around the lesion after injury to CNS [13] (Figure 2). In this regard

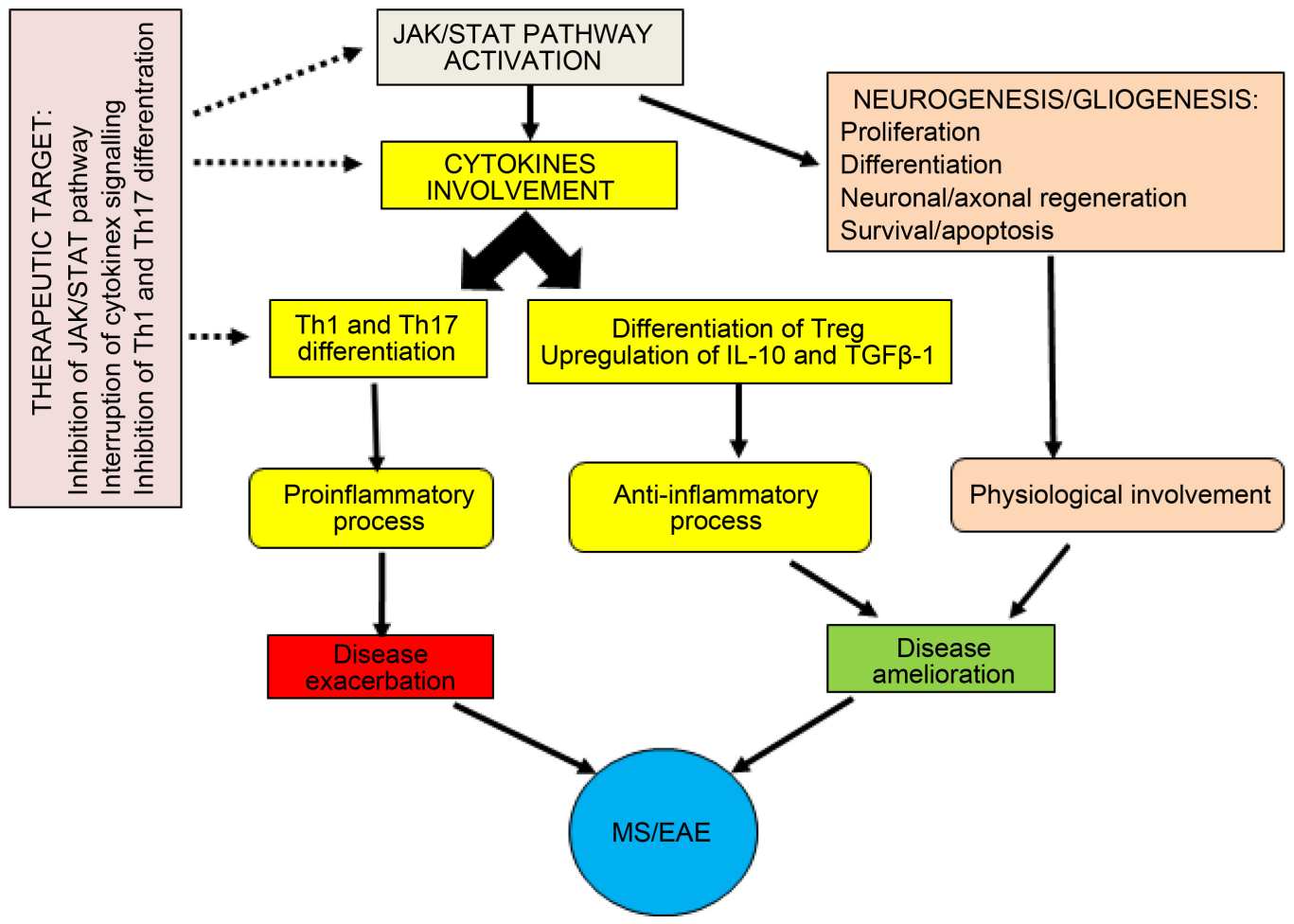

Figure 2. JAK/STAT involvement in MS. Activation of JAK/STAT pathway results in physiological or pathological process. Physiologically the pathway was involved in neurogenesis/gliogenesis; this process has a positive impact on MS/EAE as it supports processes such as axonal regeneration that will ameliorate MS condition. Cytokines involvement due to activation of this pathway result in pro- or anti-inflammatory processes. The differentiation of proinflammatory cells has negative consequences on MS/EAE as it exacerbate the condition, whereas the differentiation of anti-inflammatory cells and its cytokines favors amelioration of MS/EAE conditions thus have positive effect. JAK/STAT pathway serves as therapeutic target for amelioration of MS/EAE conditions. The pathway, proinflammatory cytokines and differentiation of Th1 and Th17 could be block by inhibitory compound and leads to inhibition of proinflammatory processes. 
STAT3 was found to be overexpressed and activated in regenerating neurons following injury to axon [51]. Previous study on adult mouse reported axon regeneration occurs after deletion of SOCS3 [52] and SOCS3 is a potent inhibitor of the pathways. After CNS injury astrogliosis rely on STAT3 activation [28]. Inhibition of STAT3 activation via JAK2 inhibition using AG490 on the proximal nerve stump can reduce neurite outgrowth [53].

\section{JAK/STAT Pathway and Cytokines in MS}

Cytokines are important in activation and regulation of immune mechanisms and inflammatory responses [24]. Cytokine networks exert their pro- and anti-inflammatory effects through multiple downstream signaling pathways [54]. In this regard, the JAK-STAT signaling pathways are involved in the signaling of several of pro- and anti-inflammatory cytokines (Table 1). In pathological condition members of JAK/STAT with complementary or antagonistic effects are often activated simultaneously [34]. Moreover, a study showed that STATs activation was significantly increased in brain and spinal cord of experimental autoimmune encephalitis (EAE) mice than in healthy control mice [55]. EAE is the animal model of MS.

STAT1 induces the activation of Th1 and IFN- $\gamma$ cytokines which have an essential role in inflammatory disease in the CNS [56]. STAT1 is required for development of Th1 cells, which are associated with proinflammatory processes [57]. Furthermore, STAT5A/B increases Th1 responses by regulating T-box transcription factor (TBX21) and interleukin-12 receptor subunit beta-2 (IL12R $\beta 2$ ) [58]. Interestingly, STAT3 takes part in Th2 differentiation and binds to Th2associated gene loci [59].

In MS IFN- $\gamma$ and IL- 6 were detected in higher levels in target tissues and they exert their effects via the activation of STAT1 and STAT3, respectively [34]. Moreover, IL-6 promotes Th17 and B cell differentiation [60], whereas, IFN- $\gamma$ induced JAK1/2-STAT1 signaling effect which was observed in classically-activated macrophages [61] [62]. IFN- $\gamma$ also involved in the acute pro-inflammatory response by inducing pro-inflammatory cytokines such as TNF- $\alpha$, IL-12, 23, 6 and chemotactic factors [62] [63], thus exacerbate disease condition in MS (Figure 2).

Table 1. JAK/STAT signalling pathways on activation of immune cells.

\begin{tabular}{ccccc}
\hline Cytokines & $\begin{array}{c}\text { Signalling } \\
\text { pathway }\end{array}$ & Effect & Cytokines secreted & Reference \\
IFN- $\gamma$ & JAK1/STAT-1 & Macrophage & $\begin{array}{c}\text { TNF- } \alpha \text {, IL-12, IL-23, IL-6, } \\
\text { chemotactic factors }\end{array}$ & [64] \\
IL-12 & JAK2/STAT-4 & $\begin{array}{c}\text { T cell } \\
\text { differentiation } \\
\text { to Th1 }\end{array}$ & IFN- $\alpha$, TNF- $\alpha$, IL-6 & [34] \\
IL-23 & JAK2/STAT-3 & Th17 & TNF- $\alpha$, !L-6, IL-17, IL-22 & [34] \\
IL-27 & JAK1/STAT-3 & Treg & IL-10, TGFR $\beta 1$ & {$[34]$} \\
\hline
\end{tabular}


JAK/STAT4 and NF- $\kappa$ B play important role in the pathways involved in pro-inflammatory processes [54]. Activation of the NF- $\kappa$ B transcription factor results in production of proinflammatory cytokines, nitric oxide (NO) and secretion of chemokines by macrophages, whereas on Dendritic cells there is increase expression of CD83, CD86, and CD40, as well as MHC class II [64] which could be important in MS pathogenesis. A study by Jiang and co-workers reported significant upregulation of JAK/STAT4 and NF- $\kappa$ B signaling pathways in EAE [65]. However, STAT4 knockout mice failed to develop EAE [66], this suggests STAT4 pathway could be irrelevant in EAE. However, CD4/STAT3 knockout mice are resistant to EAE, this shows the important role of STAT3 pathway in CNS inflammatory diseases [57].

Th17 cells produce wide range of effector cytokines such as IL-17A, IL-17F, IL-6, IL-9, IL-21, IL-22, IL-23, IL-26, and TNF $\alpha$ [67] [68]. In a brain, these cytokines induce inflammation which is characterized by infiltration of neutrophil into CNS and myelin loss [69]. High levels of IL-17 in MS lesion are associated with strong inflammatory response which could lead to exacerbations of the disease [70]. The IL-17-producing T cells (CD4+ or CD8+) have been detected in both acute and chronic MS [71]. Therefore, various studies linked this cytokine with autoimmune and chronic inflammatory conditions [72]. For instance, a study on IL-17 knockout mice shows a significant reduction in severity of EAE; this denotes the important role of this cytokine in EAE pathogenesis [72]. Moreover, the upregulation of IL-10 by immunoregulatory cytokines IL-27, suppresses IL-17, this action ultimately suppresses EAE [73]. Both Th1 and Th17 cells responses are required for EAE development [74]. IL-6/STAT3 pathway was identified as regulators of Th17 cells differentiation and function by increasing the expression and activation of the IL-6 itself, IL-17 and STAT3 [75]. IL-2/STAT5A/B signalling pathway regulates Th17 differentiation [76] by competing with STAT3 in binding to the IL17A/F locus [77]. STAT3 directly binds to IL17A/F, RAR-related orphan receptor C (RORC) and interleukin-23 receptor (IL23R) and some genes involved in Th17 differentiation to influence the regulation of the differentiation [78]. However, STAT3 upregulates anti-inflammatory cytokines such as IL-10 and TGF- $\beta 1$ to inhibit proinflammatory proteins IFN- $\gamma$, IFN- $\beta$, TNF- $\alpha$, IL-12, chemokines, MHC II, CD80, CD86 [79]. Of interest, STAT3 physically associates with Foxp3 [34].

IL2/STAT5A/B signalling pathway plays an important role in differentiation of Treg cells, in that STAT5/A directly binds the Foxp3 gene and influence the expression of the gene [80]. In addition, STAT5A/B regulates the expression of interleukin-2 receptor alpha (IL2RA), which is also required by Treg cells. Treg cells play an important role in regulating the proliferation of $\mathrm{T}$ cells but to some extent unable to inhibit Th17 mediated pathology [34]. However, Treg cells could promote Th17 differentiation due to involvement of IL-2 [81] [82].

\section{JAK/STAT Pathway as Therapeutic Target in MS}

The pathway has received attention as a therapeutic target in autoimmune dis- 
eases [17] [24] [83]. Many of the MS-promoting cytokines such as IL- $1 \beta$, TNF- $\alpha$ and especially that of IL- 6 and IL-12 either signal through or induce JAK/STAT signaling molecules [84]. Studies have implicated the JAK/STAT axis in regulating clinical manifestations of EAE [85]. JAK inhibitors produced promising result in some inflammatory diseases [86] [87]. JAK inhibitors interrupt cytokine signaling; consequently, break the inflammatory process, a useful process in MS and EAE [85] (Figure 2). Indeed, previous study reported tyrphostin B42, a JAK2 inhibitor; ameliorate EAE [84]. A study found that AZD1480 treatment is effective in suppressing clinical symptoms in EAE. Similarly Peroxisome proliferator activated receptor- $\gamma(\operatorname{PPAR} \gamma)$ and Cyclooxygenase 2 (COX2) inhibitors block the activation of JAK/STAT pathway to some extent by IL-12 thus will be able to ameliorate EAE condition [88]. In a Study using AG490 to inhibit the action of JAK2 and TYK2 as treatment of EAE showed a decrease in the activity of Th1, NK and microglial cells and reduces IL-12 levels [84]. Plumbagin (PL) and berberine are herbal compounds which inhibit the activation of JAK-STAT pathway and Th1 and Th17 cell differentiation thus prevent exacerbation of EAE model [89] [90]. Similarly, in EAE, glatiramer acetate (GA) to some extent inhibits the phosphorylation of STAT4 and STAT3 in T-cells thus exerts some effect on Th1 and Th17 cell differentiation, respectively [91]. IFN- $\beta$ action in treatment of MS requires the activity of JAK1 to activate phosphoinositide 3-kinase $(\mathrm{PI} 3 \mathrm{~K})$ and protein kinase $\mathrm{B}(\mathrm{PKB})$, this result in repression of glycogen synthase kinase-3 beta (GSK3 $\beta$ ) activity in EAE [92].

\section{Conclusion}

JAK/STAT signalling pathway involvement in MS could be physiological or pathological. This pathway plays a role in regulation of neurogenesis and gliogenesis via proliferation, differentiation, survival/apoptosis and regeneration of brain cells and neural cells precursors. JAK/STAT pathways are also involved in the signalling of both pro- and anti-inflammatory cytokines via regulation of proliferation and differentiation of immune cells responsible for the secretion of these cytokines and interference in cytokine signalling pathways for inflammatory process ameliorates or exacerbates MS pathogenesis. STAT1 induces the action of several cytokines and some are important in inflammatory diseases such as MS whereas STAT3 plays multiple roles in regulation of immune responses. In modern days, JAK/STAT pathways could serve as a potential therapeutic target for managing MS. Inhibitors of these pathways could interrupt signalling process leading to inflammation, a useful process in MS and EAE. Recently promising compounds were identified as potential inhibitors of the pathways. Researches related to JAK/STAT and MS need good attention and concern, considering the complex nature of the disease and its treatment.

\section{References}

[1] Hernández-Pedro, N.Y., Espinosa-Ramirez, G., Pérez de la Cruz, V., Pineda, B. and Sotelo, J. (2013) Initial Immunopathogenesis of Multiple Sclerosis: Innate Immune 
Response. Clinical and Developmental Immunology, 2013, Article ID: 413465.

[2] Olek, M.J. (2011) Epidemiology, Risk Factors and Clinical Features of Multiple Sclerosis in Adults.

www.uptodate.com/contents/epidemiology-and-clinical-features-of-multiple-sclero sis-in-adults

[3] Stadelmann, C. (2011) Multiple Sclerosis as a Neurodegenerative Disease: Pathology, Mechanisms and Therapeutic Implications. Current Opinion in Neurology, 24, 224-229. https://doi.org/10.1097/WCO.0b013e328346056f

[4] Oksenberg, J.R., Baranzini, S.E., Sawcer, S. and Hauser, S.L. (2008) The Genetics of Multiple Sclerosis: SNPs to Pathways to Pathogenesis. Nature Reviews Genetics, 9, 516-526. https://doi.org/10.1038/nrg2395

[5] Compston, A. and Coles, A. (2008) Multiple Sclerosis. The Lancet, 372, 1502-1517. https://doi.org/10.1016/S0140-6736(08)61620-7

[6] Vosoughi, R. and Freedman, M.S. (2010) Therapy of MS. Clinical Neurology and Neurosurgery, 112, 365-385. https://doi.org/10.1016/j.clineuro.2010.03.010

[7] Martins, T.B., Rose, J.W., Jaskowski, T.D, Wilson, A.R., Husebye, D. and Seraj, H.S. (2011) Analysis of Proinflammatory and Anti-Inflammatory Cytokine Serum Concentrations in Patients with Multiple Sclerosis by Using a Multiplexed Immunoassay. American Journal of Clinical Pathology, 136, 696-704. https://doi.org/10.1309/AJCP7UBK8IBVMVNR

[8] Batoulis, H., Addicks, K. and Kuerten, S. (2010) Emerging Concepts in Autoimmune Encephalomyelitis beyond the CD4/ $\mathrm{T}_{\mathrm{H}} 1$ Paradigm. Annals of Anatomy, 192, 179-193.

[9] Ramagopalan, S.V., Dobson, R., Meier, U.C. and Giovannoni, G. (2010) Multiple Sclerosis: Risk Factors, Prodromes and Potential Causal Pathways. The Lancet Neurology, 9, 727-739. https://doi.org/10.1016/S1474-4422(10)70094-6

[10] Romme, C.J., Börnsen, L., Hesse, D., Krakauer, M. Sørensen, P.S. and Søndergaard, H.B. (2012) Cellular Sources of Dysregulated Cytokines in Relapsing-Remitting Multiple Sclerosis. Journal of Neuroinflammation, 9, 215.

[11] Kasper, L.H. and Shoemaker, J. (2010) Multiple Sclerosis Immunology: The Healthy Immune System vs the Multiple Sclerosis Immune System. Neurology, 74, S2-S8. https://doi.org/10.1212/WNL.0b013e3181c97c8f

[12] Rodgers, J.M. and Miller, S.D. (2012) Cytokine Control of Inflammation and Repair in the Pathology of Multiple Sclerosis. Yale Journal of Biology and Medicine, 85, 447-468.

[13] Nicolas, C.S., Amici, M., Bortolotto, Z.A., Doherty, A., Csaba, Z., Fafouri, A., Dournaud, P., Gressens, P., Collingridge, G.L. and Peineau, S. (2013) The Role of JAK-STAT Signaling within the Central Nervous System. JAK-STAT, 2, e22925. https://doi.org/10.4161/jkst.22925

[14] Furqan, M., Mukhi, N., Lee, B. and Liu, D. (2013) Dysregulation of JAK-STAT pathway in Hematological Malignancies and JAK Inhibitors for Clinical Application. Biomarker Research, 1, 5. https://doi.org/10.1186/2050-7771-1-5

[15] Harrison, D.A. (2012) The JAK/STAT Pathway. Cold Spring Harbor Perspectives in Biology, 4, pii:a011205. https://doi.org/10.1101/cshperspect.a011205

[16] Campbell, I.L. (2005) Cytokine-Mediated Inflammation, Tumorogenesis, and Disease-Associated JAK/STAT/SOCS Signaling Circuits in the Central Nervous System. Brain Research Reviews, 48, 166-177.

[17] Seavey, M.M. and Dobrzanski, P. (2012) The Many Faces of Janus Kinase. Biochemical Pharmacology, 83, 1136-1145. 
[18] O’Sullivan, L.A., Liongue, C., Lewis, R.S., Stephenson, S.E. and Ward, A.C. (2007) Cytokine Receptor Signaling through the Jak-Stat-Socs Pathway in Disease. Molecular Immunology, 44, 2497-2506.

[19] Mohr, A., Chatain, N., Domoszlai, T., Rinis, N., Sommerauer, M., Vogt, M. and Müller-Newen, G. (2012) Dynamics and Non-Canonical Aspects of JAK/STAT Signalling. European Journal of Cell Biology, 91, 524-532.

[20] Zhuang, S. (2013) Regulation of STAT Signaling by Acetylation. Cell Signal, 25, 1924-1931.

[21] Santos, C.I. and Costa-Pereira, A.P. (2011) Signal Transducers and Activators of Transcription-From Cytokine Signalling to Cancer Biology. Biochimica et Biophysica Acta, 1816, 38-49.

[22] Benveniste, E.N., Liu, Y., McFarland, B.C. and Qin, H. (2014) Involvement of the Janus Kinase/Signal Transducer and Activator of Transcription Signaling Pathway in Multiple Sclerosis and the Animal Model of Experimental Autoimmune Encephalomyelitis. Journal of Interferon and Cytokine Research, 34, 577-588. https://doi.org/10.1089/jir.2014.0012

[23] Levy, D.E. and Darnell, J.J. (2002) Stats: Transcriptional Control and Biological Impact. Nature Reviews Molecular Cell Biology, 3, 651-662.

https://doi.org/10.1038/nrm909

[24] O’Shea, J.J. and Plenge, R. (2012) JAK and STAT Signaling Molecules in Immunoregulation and Immune-Mediated Disease. Immunity, 36, 542-550.

https://doi.org/10.1016/j.immuni.2012.03.014

[25] Cao, F., Hata, R., Zhu, P., Nakashiro, K. and Sakanaka, M. (2010) Conditional Deletion of STAT3 Promotes Neurogenesis and Inhibits Astrogliogenesis in Neural Stem Cells. Biochemical and Biophysical Research Communications, 394, 843-847.

[26] He, F., Ge, W., Martinowich, K., Becker-Catania, S., Coskun, V., Zhu, W., Wu, H., Castro, D., Guillemot, F., Fan, G., de Vellis, J. and Sun, Y.E. (2005) A Positive Autoregulatory Loop of JAK-STAT Signaling Controls the Onset of Astrogliogenesis. Nature Neuroscience, 8, 616-625. https://doi.org/10.1038/nn1440

[27] de la Iglesia, N., Puram, S.V. and Bonni, A. (2009) STAT3 Regulation of Glioblastoma Pathogenesis. Current Molecular Medicine, 9, 580-590. https://doi.org/10.2174/156652409788488739

[28] Herrmann, J.E., Imura, T., Song, B., Qi, J., Ao, Y., Nguyen, T.K., Korsak, R.A., Takeda, K., Akira, S. and Sofroniew, M.V. (2008) STAT3 Is a Critical Regulator of Astrogliosis and Scar Formation After Spinal Cord Injury. Journal of Neuroscience, 28, 7231-7243. https://doi.org/10.1523/JNEUROSCI.1709-08.2008

[29] Wells, J.A. and de Vos, A.M. (1996) Hematopoietic Receptor Complexes. Annual Review of Biochemistry, 65, 609-634. https://doi.org/10.1146/annurev.bi.65.070196.003141

[30] Schindler, C., Levy, D.E. and Decker, T. (2007) JAK-STAT Signaling: From Interferons to Cytokines. Journal of Biological Chemistry, 282, 20059-20063.

[31] Kisseleva, T., Bhattacharya, S., Braunstein, J. and Schindler, C.W. (2002) Signaling through the JAK/STAT Pathway, Recent Advances and Future Challenges. Gene, 285, 1-24.

[32] Srivastava, P., Mujtaba, M.A. and Singhal, M. (2012) Gene and Cytokines Expression of Multiple Sclerosis and Its Therapeutic Regimen: A Systemic Review. International Journal of Drug Development and Research, 4, 55-66.

[33] Valentino, L. and Pierre, J. (2006) JAK/STAT Signal Transduction: Regulators and Implication in Hematological Malignancies. Biochemical Pharmacology, 71, 713- 
721.

[34] Egwuagu, C.E. (2009) STAT3 in CD4 ${ }^{+}$T helper Cell Differentiation and Inflammatory Diseases. Cytokine, 47, 149-156.

[35] Vera, J., Rateitschak, K., Lange, F., Kossow, C., Wolkenhauer, O. and Jaster, R. (2011) Systems Biology of JAK-STAT Signalling in Human Malignancies. Progress in Biophysics and Molecular Biology, 106, 426-434.

[36] Ihle, J.N. (2001) The Stat Family in Cytokine Signaling. Current Opinion in Cell Biology, 13, 211-217.

[37] Cayre, M., Canoll, P. and Goldman, J.E. (2009) Cell Migration in the Normal and Pathological Postnatal Mammalian Brain. Progress in Neurobiology, 88, 41-63.

[38] Bauer, S. (2009) Cytokine Control of Adult Neural Stem Cells. Annals of the New York Academy of Sciences, 1153, 48-56. https://doi.org/10.1111/j.1749-6632.2009.03986.x

[39] Gómez-Nicola, D., Valle-Argos, B., Pallas-Bazarra, N. and Nieto-Sampedro, M. (2011) Interleukin-15 Regulates Proliferation and Self-Renewal of Adult Neural Stem Cells. Molecular Biology of the Cell, 22, 1960-1970. https://doi.org/10.1091/mbc.E11-01-0053

[40] Bonni, A., Sun, Y., Nadal-Vicens, M., Bhatt, A., Frank, D.A., Rozovsky, I., Stahl, N., Yancopoulos, G.D. and Greenberg, M.E. (1997) Regulation of Gliogenesis in the Central Nervous System by the JAK-STAT Signaling Pathway. Science, 278, 477483. https://doi.org/10.1126/science.278.5337.477

[41] Garza, J.C., Guo, M., Zhang, W. and Lu, X.Y. (2008) Leptin Increases Adult Hippocampal Neurogenesis in Vivo and in Vitro. Journal of Biological Chemistry, 283, 18238-18247. https://doi.org/10.1074/jbc.M800053200

[42] Kim, Y.H., Chung, J.I., Woo, H.G., Jung, Y.S., Lee, S.H., Moon, C.H., Suh-Kim, H. and Baik, E.J. (2010) Differential Regulation of Proliferation and Differentiation in Neural Precursor Cells by the JAK Pathway. Stem Cells, 28, 1816-1828. https://doi.org/10.1002/stem.511

[43] Müller, S., Chakrapani, B.P., Schwegler, H., Hofmann, H.D. and Kirsch, M. (2009) Neurogenesis in the Dentate Gyrus Depends on Ciliary Neurotrophic Factor and Signal Transducer and Activator of Transcription 3 Signaling. Stem Cells, 27, 431441. https://doi.org/10.1634/stemcells.2008-0234

[44] Hirsch, M., Knight, J., Tobita, M., Soltys, J., Panitch, H. and Mao-Draayer, Y. (2009) The Effect of Interferon-Beta on Mouse Neural Progenitor Cell Survival and Differentiation. Biochemical and Biophysical Research Communications, 388, 181-186.

[45] Lum, M., Croze, E., Wagner, C., McLenachan, S., Mitrovic, B. and Turnley, A.M. (2009) Inhibition of Neurosphere Proliferation by IFN-Gamma but Not IFN Beta Is Coupled to Neuronal Differentiation. Journal of Neuroimmunology, 206, 32-38. https://doi.org/10.1016/j.jneuroim.2008.10.009

[46] Arscott, W.T., Soltys, J., Knight, J. and Mao-Draayer, Y. (2011) Interferon $\beta$-1b Directly Modulates Human Neural Stem/Progenitor Cell Fate. Brain Research, 1413, 1-8. https://doi.org/10.1016/j.brainres.2011.07.037

[47] Mangoura, D., Pelletiere, C., Leung, S., Sakellaridis, N. and Wang, D.X. (2000) Prolactin Concurrently Activates Src-PLD and JAK/Stat Signaling Pathways to Induce Proliferation While Promoting Differentiation in Embryonic Astrocytes. International Journal of Developmental Neuroscience, 18, 693-704.

[48] Gupta, S., Mishra, K., Surolia, A. and Banerjee, K. (2011) Suppressor of Cytokine Signalling-6 Promotes Neurite Outgrowth via JAK2/STAT5-Mediated Signalling Pathway, Involving Negative Feedback Inhibition. PLoS ONE, 6, e26674. 
https://doi.org/10.1371/journal.pone.0026674

[49] Mäkelä, J., Koivuniemi, R., Korhonen, L. and Lindholm, D. (2010) InterferonGamma Produced by Microglia and the Neuropeptide PACAP Have Opposite Effects on the Viability of Neural Progenitor Cells. PLOS ONE, 5, e11091.

https://doi.org/10.1371/journal.pone.0011091

[50] Fontaine, R.H., Cases, O., Lelièvre, V., Mesplès, B., Renauld, J.C., Loron, G., Degos, V., Dournaud, P., Baud, O. and Gressens, P. (2008) IL-9/IL-9 Receptor Signaling Selectively Protects Cortical Neurons against Developmental Apoptosis. Cell Death \& Differentiation, 15, 1542-1552. https://doi.org/10.1038/cdd.2008.79

[51] Schwaiger, F.W., Hager, G., Schmitt, A.B., Horvat, A., Hager, G., Streif, R., Spitzer, C., Gamal, S., Breuer, S., Brook, G.A., Nacimiento, W. and Kreutzberg, G.W. (2000) Peripheral but Not Central Axotomy Induces Changes in Janus Kinases (JAK) and Signal Transducers and Activators of Transcription (STAT). European Journal of Neuroscience, 12, 1165-1176. https://doi.org/10.1046/j.1460-9568.2000.00005.x

[52] Smith, P.D., Sun, F., Park, K.K., Cai, B., Wang, C., Kuwako, K., Martinez-Carrasco, I., Connolly, L. and He, Z. (2009) SOCS3 Deletion Promotes Optic Nerve Regeneration in Vivo. Neuron, 64, 617-623. https://doi.org/10.1016/j.neuron.2009.11.021

[53] Qiu, J., Cafferty, W.B., McMahon, S.B. and Thompson, S.W. (2005) Conditioning Injury-Induced Spinal Axon Regeneration Requires Signal Transducer and Activator of Transcription 3 Activation. Journal of Neuroscience, 25, 1645-1653. https://doi.org/10.1523/JNEUROSCI.3269-04.2005

[54] Greve, B., Weissert, R., Hamdi, N., Bettelli, E., Sobel, R.A., Coyle, A., Kuchroo, V.K., Rajewsky, K. and Schmidt-Supprian, M. (2007) I $k$ B Kinase $2 / \beta$ Deficiency Controls Expansion of Autoreactive T Cells and Suppresses Experimental Autoimmune Encephalomyelitis. Journal of Immunology, 179, 179-185. https://doi.org/10.4049/jimmunol.179.1.179

[55] Nishikomori, R., Usui, T., Wu, C.Y., Morinobu, A., O’Shea, J.J. and Strober, W. (2002) Activated STAT4 Has an Essential Role in Th1 Differentiation and Proliferation That Is Independent of Its Role in the Maintenance of IL-12R Beta 2 Chain Expression and Signaling. Journal of Immunology, 169, 4388-4398. https://doi.org/10.4049/jimmunol.169.8.4388

[56] Nishibori, T., Tanabe, Y., Su, L. and David, M. (2004) Impaired Development of $\mathrm{CD} 4{ }^{+} \mathrm{CD} 25^{+}$Regulatory $\mathrm{T}$ Cells in the Absence of STAT1: Increased Susceptibility to Autoimmune Disease. Journal of Experimental Medicine, 199, 25-34. https://doi.org/10.1084/jem.20020509

[57] Liu, X., Lee, Y.S., Yu, C.R. and Egwuagu, C.E. (2008) Loss of STAT3 in CD4+ T Cells Prevents Development of Experimental Autoimmune Diseases. Journal of Immunology, 180, 6070-6076. https://doi.org/10.4049/jimmunol.180.9.6070

[58] Liao, W., Lin, J.X., Wang, L., Li, P. and Leonard, W.J. (2011) Modulation of Cytokine Receptors by IL-2 Broadly Regulates Differentiation into Helper T Cell Lineages. Nature Immunology, 12, 551-559. https://doi.org/10.1038/ni.2030

[59] Stritesky, G.L., Muthukrishnan, R., Sehra, S., Goswami, R., Pham, D., Travers, J., Nguyen, E.T., Levy, D.E. and Kaplan, M.H. (2011) The Transcription Factor STAT3 Is Required for T Helper 2 Cell Development. Immunity, 34 39-49. https://doi.org/10.1016/j.immuni.2010.12.013

[60] Carpentier, P.A., Duncan, D.S. and Miller, S.D. (2008) Glial Toll-Like Receptor Signaling in Central Nervous System Infection and Autoimmunity. Brain, Behavior, and Immunity, 22, 140-147. https://doi.org/10.1016/j.bbi.2007.08.011

[61] Flavell, R.A., Sanjabi, S., Wrzesinski, S.H. and Licona-Limon, P. (2010) The Polarization of Immune Cells in the Tumour Environment by TGF Beta. Nature Review 
Immunology, 10, 554-567. https://doi.org/10.1038/nri2808

[62] Cao, L. and He, C. (2013) Polarization of Macrophages and Microglia in Inflammatory Demyelination. Neuroscience Bulletin, 29, 189-198.

https://doi.org/10.1007/s12264-013-1324-0

[63] Lawrence, T. and Natoli, G. (2011) Transcriptional Regulation of Macrophage Polarization: Enabling Diversity with Identity. Nature Review Immunology, 11, 750-761. https://doi.org/10.1038/nri3088

[64] Mansilla, M.J., Montalban, X. and Espejo, C. (2012) Heat Shock Protein 70: Roles in Multiple Sclerosis. Molecular Medicine, 18, 1018-1028.

[65] Jiang, Z., Li, H., Fitzgerald, D.C., Zhang, G.Z. and Rostami, A. (2009) MOG $35-55$ i.v Suppresses Experimental Autoimmune Encephalomyelitis Partially through Modulation of Th17 and JAK/STAT Pathways. European Journal of Immunology, 39, 789-799. https://doi.org/10.1002/eji.200838427

[66] Boyton, R.J., Davies, S., Marden, C., Fantino, C., Reynolds, C., Portugal, K, Dewchand, H. and Altmann, D.M. (2005) Stat4-Null Non-Obese Diabetic Mice: Protection from Diabetes and Experimental Allergic Encephalomyelitis, but with Concomitant Epitope Spread. International Immunology, 17, 1157-1165.

https://doi.org/10.1093/intimm/dxh293

[67] Bettelli, E., Korn, T. and Kuchroo, V.K. (2007) Th17: The Third Member of the Effector T Cell Trilogy. Current Opinion in Immunology, 19, 652-657.

https://doi.org/10.1016/j.coi.2007.07.020

[68] Jadidi-Niaragh, F. and Mirshafiey, A. (2011) Th17 Cell, the New Player of Neuroinflammatory Process in Multiple Sclerosis. Scandinavian Journal of Immunology, 74, 1-13. https://doi.org/10.1111/j.1365-3083.2011.02536.x

[69] Iwakura, Y. and Ishigame, H. (2006) The IL-23/IL-17 Axis in Inflammation. Journal of Clinical Investigation, 116, 1218-1222. https://doi.org/10.1172/JCI28508

[70] Huppert, J., Closhen, D., Croxford, A., White, R., Kulig, P., Pietrowski, E., Bechmann, I., Becher, B., Luhmann, H.J., Waisman, A. and Kuhlmann, C.R. (2010) Cellular Mechanisms of IL-17-Induced Blood-Brain Barrier Disruption. FASEB Journal, 24, 1023-1034. https://doi.org/10.1096/fj.09-141978

[71] Tzartos, J.S., Friese, M.A., Craner, M.J., Palace, J., Newcombe, J., Esiri, M.M. and Fugger, L. (2008) Interleukin-17 Production in Central Nervous System-Infiltrating T Cells and Glial Cells Is Associated with Active Disease in Multiple Sclerosis. American Journal of Pathology, 172, 146-155. https://doi.org/10.2353/ajpath.2008.070690

[72] Komiyama, Y., Nakae, S., Matsuki, T., Nambu, A., Ishigame, H., Kakuta, S., Sudo, K. and Iwakura, Y. (2006) IL-17 Plays an Important Role in the Development of Experimental Autoimmune Encephalomyelitis. Journal of Immunology, 177, 566573. https://doi.org/10.4049/jimmunol.177.1.566

[73] Fitzgerald, D.C., Ciric, B., Touil, T., Harle, H., Grammatikopolou, J., Das Sarma, J., Gran, B., Zhang, G.X. and Rostami, A. (2007) Suppressive Effect of IL-27 on Encephalitogenic Th17 Cells and the Effector Phase of Experimental Autoimmune Encephalomyelitis. Journal of Immunology, 179, 3268-3275. https://doi.org/10.4049/jimmunol.179.5.3268

[74] Stromnes, I.M., Cerretti, L.M., Liggitt, D., Harris, R.A. and Goverman, J.M. (2008) Differential Regulation of Central Nervous System Autoimmunity by $\mathrm{T}_{\mathrm{H}} 1$ and $\mathrm{T}_{\mathrm{H}} 17$ Cells. Nature Medicine, 14, 337-342. https://doi.org/10.1038/nm1715

[75] Camporeale, A. and Poli, V. (2012) IL-6, IL-17 and STAT3: A Holy Trinity in Auto-Immunity? Frontiers in Bioscience, 17, 2306-2326. https://doi.org/10.2741/4054 
[76] Laurence, A., Tato, C.M., Davidson, T.S., Kanno, Y., Chen, Z., Yao, Z., Blank, R.B., Meylan, F., Siegel, R., Hennighausen, L., Shevach, E.M. and O’Shea, J.J. (2007) Interleukin-2 Signaling via STAT5 Constrains T Helper 17 Cell Generation. Immunity, 26, 371-381. https://doi.org/10.1016/j.immuni.2007.02.009

[77] Yang, X.P., Ghoreschi, K., Steward-Tharp, S.M., Rodriguez-Canales, J., Zhu, J., Grainger, J.R., Hirahara, K., Sun, H.W., Wei, L., Vahedi, G., Kanno, Y., O’Shea, J.J. and Laurence, A. (2011) Opposing Regulation of the Locus Encoding IL-17 through Direct, Reciprocal Actions of STAT3 and STAT5. Nature Immunology, 12, 247-254. https://doi.org/10.1038/ni.1995

[78] Durant, L., Watford, W.T., Ramos, H.L., Laurence, A., Vahedi, G., Wei, L., Takahashi, H., Sun, H.W., Kanno, Y., Powrie, F. and O'Shea, J.J. (2010) Diverse Targets of the Transcription Factor STAT3 Contribute to T Cell Pathogenicity and Homeostasis. Immunity, 32, 605-615. https://doi.org/10.1016/j.immuni.2010.05.003

[79] El-Kasmi, K.C., Holst, J., Coffre, M., Mielke, L., de Pauw, A., Lhocine, N., Smith, A.M., Rutschman, R., Kaushal, D., Shen, Y., Suda, T., Donnelly, R.P., Myers Jr., M.G., Alexander, W., Vignali, D.A., Watowich, S.S., Ernst, M., Hilton, D.J. and Murray, P.J. (2006) General Nature of the STAT3-Activated Anti-Inflammatory Response. Journal of Immunology, 177, 7880-7888. https://doi.org/10.4049/jimmunol.177.11.7880

[80] Burchill, M.A., Yang, J., Vogtenhuber, C., Blazar, B.R. and Farrar, M.A. (2007) IL-2 Receptor Beta-Dependent STAT5 Activation Is Required for the Development of Foxp3 $3^{+}$Regulatory T Cells. Journal of Immunology, 178, 280-290. https://doi.org/10.4049/jimmunol.178.1.280

[81] Chen, Y., Haines, C.J., Gutcher, I., Hochweller, K., Blumenschein, W.M., McClanahan, T., Hämmerling, G., Li, M.O., Cua, D.J. and McGeachy, M.J. (2011) Foxp3 ${ }^{+}$ Regulatory T Cells Promote T Helper 17 Cell Development in Vivo through Regulation of Interleukin-2. Immunity, 34, 409-421. https://doi.org/10.1016/j.immuni.2011.02.011

[82] Pandiyan, P., Conti, H.R., Zheng, L., Peterson, A.C., Mathern, D.R., HernandezSantos, N., Edgerton, M., Gaffen, S.L. and Lenardo, M.J. (2011) CD $4^{+} \mathrm{CD} 25^{+}$Foxp $3^{+}$ Regulatory T Cells Promote Th17 Cells in Vitro and Enhance Host Resistance in Mouse Candida albicans Th17 Cell Infection Model. Immunity, 34, 422-434. https://doi.org/10.1016/j.immuni.2011.03.002

[83] Lin, Y., Wang, F. and Zhang, G.L. (2014) Natural Products and Their Derivatives Regulating the Janus Kinase/Signal Transducer and Activator of Transcription Pathway. Journal of Asian Natural Products and Research, 16, 800-812. https://doi.org/10.1080/10286020.2014.929573

[84] Bright, J.J., Du, C. and Sriram, S. (1999) Tyrphostin B42 Inhibits IL12-Induced Tyrosine Phosphorylation and Activation of Janus Kinase-2 and Prevents Experimental Allergic Encephalomyelitis. Journal of Immunology, 162, 6255-6262.

[85] Liu, Y., Holdbrooks, A.T., De Sarno, P., Rowse, A.L., Yanagisawa, L.L., McFarland, B.C. and Harringt, L.E. (2014) Therapeutic Efficacy of Suppressing the JAK/STAT Pathway in Multiple Models of EAE. Journal of Immunology, 192, 59-72. https://doi.org/10.4049/jimmunol.1301513

[86] Ghoreschi, K., Jesson, M.I., Li, X., Lee, J.L., Ghosh, S., Alsup, J.W., Warner, J.D., Tanaka, M., Steward-Tharp, S.M., Gadina, M., Thomas, C.J., Minnerly, J.C., Storer, C.E., LaBranche, T.P., Radi, Z.A., Dowty, M.E., Head, R.D., Meyer, D.M., Kishore, N. and O'Shea, J.J. (2011) Modulation of Innate and Adaptive Immune Responses by Tofacitinib (CP-690,550). Journal of Immunology, 186, 4234-4243.

https://doi.org/10.4049/jimmunol.1003668 
[87] Van Vollenhoven, R.F., Fleischmann, R., Cohen, S., Lee, E.B., Garcia Meijide, J.A., Wagner, S. Forejtova, S., Zwillich, S.H., Gruben, D., Koncz, T., Wallenstein, G.V., Krishnaswami, S., Bradley, J.D. and Wilkinson, B. (2012) Tofacitinib or Adalimumab versus Placebo in Rheumatoid Arthritis. The New England Journal of Medicine, 367, 508-519. https://doi.org/10.1056/NEJMoa1112072

[88] Muthian, G., Raikwar, H.P., Rajasingh, J. and Bright, J.J. (2006) 1,25 Dihydroxyvitamin-D3 Modulates JAK-STAT Pathway in IL-12/IFN Gamma Axis Leading to Th1 Response in Experimental Allergic Encephalomyelitis. Journal of Neuroscience Research, 83, 1299-1309. https://doi.org/10.1002/jnr.20826

[89] Qin, X., Guo, B.T., Wan, B., Fang, L., Lu, L., Wu, L., Zang, Y.Q. and Zhang, J.Z. (2010) Regulation of Th1 and Th17 Cell Differentiation and Amelioration of Experimental Autoimmune Encephalomyelitis by Natural Product Compound Berberine. Journal of Immunology, 185, 1855-1863.

https://doi.org/10.4049/jimmunol.0903853

[90] Jia, Y., Jing, J., Bai, Y., Li, Z., Liu, L., Luo, J., Liu, M. and Chen, H. (2011) Amelioration of Experimental Autoimmune Encephalomyelitis by Plumbagin through DownRegulation of JAK-STAT and NF- $\kappa$ B Signaling Pathways. PLoS ONE, 6, e27006. https://doi.org/10.1371/journal.pone.0027006

[91] Chen, C., Liu, X., Wan, B. and Zhang, J.Z. (2009) Regulatory Properties of Copolymer I in Th17 Differentiation by Altering STAT3 Phosphorylation. Journal of Immunology, 183, 246-253.

[92] Wang, H., Brown, J., Garcia, C.A., Tang, Y., Benakanakere, M.R., Greenway, T., Pascale, A., Denis, F.K. and Michael, M. (2011). The Role of Glycogen Synthase Kinase 3 in Regulating IFN-Beta-Mediated IL-10 Production. Journal of Immunology, 186, 675-684. https://doi.org/10.4049/jimmunol.1001473

Submit or recommend next manuscript to OALib Journal and we will provide best service for you:

- Publication frequency: Monthly

- 9 subject areas of science, technology and medicine

- Fair and rigorous peer-review system

- Fast publication process

- Article promotion in various social networking sites (LinkedIn, Facebook, Twitter, etc.)

- Maximum dissemination of your research work

Submit Your Paper Online: Click Here to Submit

Or Contact service@oalib.com 